\title{
Museum Songket Palembang Dengan Pendekatan ArsiteKTUR NeO-VERNAKULAR
}

\author{
Abdul Aziz Arrosyid, Samsudi, Ummul Mustaqimah \\ Program Studi Arsitektur \\ Universitas Sebelas Maret Surakarta \\ Email : mozaique08@gmail.com
}

\begin{abstract}
Traditional weaving as a national cultural heritage is being abandoned, including songket in Palembang city. Songket weaving craft has been abandoned due to the limited process of the making, expensive raw materials, and competitiveness, either other crafters or modern weaving. There are hundreds of Palembang songket motifs that have not been documented and collected well. Only 77 motifs which have been registered as intellectual property rights. The lack attention of this matter would give possibility for neighboring countries to claim it such an accident ever exist. Songket Museum is needed as conservation center, exhibition, research, and songket craft workshop. Neo-Vernacular Architecture approach is used to make museum architectural design which is in line the cultural values of Palembang in contemporary design. The design issue is how to apply the principles of NeoVernacular Architecture into Palembang Songket Museum design. The method is designing the museum by taking both the physical and non-physical elements of local culture. Beside, reinterpretation the shape and philosophycal value of local architecture and Palembang songket are apllied in a new composition of Neo-Vernacular Architecture. The result is a design of Palembang Songket Museum which applies Neo-Vernacular Architecture principles.
\end{abstract}

Keywords: Architecture, Neo-Vernacular, Palembang Songket, Songket Museum.

\section{PENDAHULUAN}

Indonesia memiliki kekayaan seni dan budaya yang berragam. Dari Sabang hingga Merauke terdapat berbagai bentuk kesenian seperti tarian, upacara adat, bangunan, hingga pakaian, dan kerajinan khas. Salah satunya kerajinan kain tradisional yang biasa disebut kain tenun. Palembang sebagai salah satu kota tertua di Indonesia mewarisi kerajinan tenun yang disebut songket. Sejak zaman Kerajaan Sriwijaya, Palembang menjadi kota pelabuhan yang ramai oleh kapal dari negeri seperti Cina, India, dan Arab untuk berdagang. Pertukaran barang seperti benang emas, benang perak, dan sutera dengan katun dari Sumatera (Kartiwa, 1986: 4) diikuti dengan pertukaran budaya. Salah satunya masyarakat Palembang kemudian mengenal teknik menyungkit dari India, dengan alat yang disebut gedogan.

Menyongket merupakan keahlian yang harus dikuasai gadis Palembang (Jusuf, 2012: 14). Pada masa lalu, kaum perempuan mengisi waktunya di serambi rumah seraya menyongket. Kini seiring perkembangan zaman, kegiatan menyungkit mulai ditinggalkan. Kaum perempuan memilih bekerja di kantor atau menjadi pegawai negeri yang lebih terjamin pendapatannya. Padahal tingkat serapan tenaga kerja di Kota Palembang semakin berat akibat laju pertumbuhan penduduk berdasarkan data BPS Palembang (2014) mencapai 1,70\%. Sedangkan lapangan pekerjaan hanya mampu menyerap 5.431 jiwa atau $41,28 \%$ dari jumlah penduduk.

Salah satu alternatif lapangan pekerjaan yang memiliki prospek menarik adalah Industri Kecil Menengah (IKM). Dinas Perindustrian Perdagangan dan Koperasi Kota Palembang menunjukkan industri sandang (tekstil) pada tahun 2011 membutuhkan 5.458 tenaga kerja, kemudian tahun 2012 meningkat menjadi 5.526 tenaga kerja dan 5.667 tenaga kerja pada tahun 2013.

Songket Palembang menurut Kartiwa (1986: 33) terdiri dari dua karakter berdasarkan penempatan motif hiasnya, yaitu songket dengan hiasan penuh (songket lepus) dan songket tawur dengan hiasan menyebar, tidak penuh atau bertabur. Motif yang 
digunakan umumnya stilasi dari tanaman seperti sulur, rebung, bunga, dan menghindari bentuk makhluk hidup. Karakter dan ragam motif tersebut menjadi penamaan untuk jenis songket tersebut. Tercatat 77 motif yang didaftarkan dengan 22 di antaranya telah disahkan oleh Direktorat Jendral Hak Kekayaan Intelektual Kementerian Hukum dan HAM. Masih terdapat ratusan motif baik yang lama maupun inovasi perajin baru yang belum terdokumentasi dengan baik. Persoalan hak cipta ini penting agar motif songket Palembang terhindar dari upaya klaim negara lain.

Upaya yang perlu dilakukan untuk menjaga kelestarian warisan budaya adalah dengan mendirikan museum. Pasal 18 Undang-Undang Nomor 11 Tahun 2010 tentang Cagar Budaya mengamanatkan museum sebagai lembaga non-profit yang melakukan upaya pelestarian benda cagar budaya dengan tujuan pengkajian, pendidikan, dan rekreasi. Untuk menjaga warisan budaya songket Palembang, diperlukan suatu wadah berupa Museum Songket yang menyimpan, merawat, mendokumentasikan, dan memamerkan kain songket maupun benda-benda lain yang terkait kerajinan songket Palembang.

Selain memamerkan, Museum Songket juga membuka kelas-kelas pelatihan, dan pembinaan kepada masyarakat, terutama generasi muda, sehingga dapat mempelajari kerajinan songket agar kemudian menjadi bekal keterampilan dan dapat menjadi salah satu sumber perekonomian masyarakat.

Pendekatan Arsitektur Neo-Vernakular digunakan untuk mendapatkan gubahan arsitektur yang mengacu pada bahasa setempat dengan mengambil elemen-elemen fisik maupun non fisik, seperti budaya, pola pikir, kepercayaan/pandangan terhadap ruang, nilai filosofi, dan religi, menjadi konsep dan kriteria perancangan ke dalam bentuk kontemporer (Sumalyo, 1997: 452). Dengan pendekatan tersebut, Museum Songket Palembang dapat memenuhi fungsi museum sebagai bangunan yang dapat melindungi, menyimpan, dan merawat benda koleksi songket, juga mengandung nilai filosofi songket dan nilai budaya Palembang seperti pada arsitektur rumah Limas, yang digubah dan diinterpretasi ulang dalam bentuk kontemporer.

\section{METODE}

Metode perancangan desain dimulai dari proses pengumpulan data mengenai songket Palembang. Data mengenai wastra tradisional Nusantara dan songket Palembang dihimpun dari studi literatur, survei ke Kampung Songket 30 Ilir Palembang, dan Museum Balaputradewa untuk mendapatkan informasi mengenai koleksi peninggalan kerajinan songket Palembang yang dimiliki Pemerintah Kota Palembang.

Pemahaman mengenai museum wastra didapatkan dengan mengumpulkan literatur terkait. Juga dilakukan studi observasi ke museum-museum lain yang kemudian dapat dirujuk sebagai preseden. Pendekatan desain arsitektur membutuhkan landasan teori yang diperoleh dari literatur. Kemudian dilakukan studi lapangan ke Kampung Songket 30 Ilir Palembang, di mana masih terdapat banyak rumah-rumah panggung tradisional. Survei lapangan tersebut sekaligus untuk mendapatkan data tapak yang akan dipilih sebagai lokasi museum, selain juga melalui citra satelit dengan menggunakan aplikasi Google Earth.

Data yang terhimpun kemudian digunakan dalam proses analisis perancangan Museum Songket Palembang. Analisis perancangan dilakukan dengan melakukan analisis program fungsional museum, analisis performansi, dan analisis pendekatan arsitektur.

Analisis pemrograman fungsional museum dilakukan dengan mengidentifikasi penggunaan Museum Songket Palembang, di antaranya pelaku kegiatan, jenis kegiatan, dan pola kegiatan.

Analisis performansi menerjemahkan kebutuhan pelaku kegiatan maupun objek pamer museum ke dalam persyaratan ruang, persyaratan besaran ruang, program ruang, dan pemilihan tapak sesuai dengan bangunan Museum Songket yang direncanakan.

Analisis pendekatan arsitektur merupakan proses analisis masalah sekuensi ruang pamer, massa bangunan, tampilan, pengolahan tapak, pemilhan material, sistem utilitas, dan struktur bangunan sesaui dengan pendekatan Arsitektur Neo-Vernakular. 


\section{ANALISIS}

\subsection{Analisis Peruangan}

1. Kegiatan Pameran

Tabel 1. Kebutuhan Ruang Pameran

\begin{tabular}{|c|c|}
\hline $\begin{array}{c}\text { Jenis } \\
\text { Kegiatan } \\
\end{array}$ & $\begin{array}{c}\text { Kebutuhan } \\
\text { Ruang }\end{array}$ \\
\hline Penerimaan & $\begin{array}{l}\text {-Taman } \\
\text {-Lobbi }\end{array}$ \\
\hline $\begin{array}{l}\text { Pameran } \\
\text { tetap }\end{array}$ & $\begin{array}{l}\text {-Galeri Sriwijaya } \\
\text {-Galeri Kesultanan } \\
\text { Palembang } \\
\text {-Ruang Penjajahan } \\
\text {-Lorong Kemerdekaan } \\
\text {-Galeri alat dan bahan }\end{array}$ \\
\hline $\begin{array}{l}\text { Pameran } \\
\text { temporer }\end{array}$ & $\begin{array}{l}\text {-Eksibitional hall } \\
\text {-Atrium }\end{array}$ \\
\hline
\end{tabular}

Tabel 1 menerangkan kebutuhan ruang kegiatan pameran.

\section{Kegiatan Workshop dan Pendidikan}

Tabel 2. Kebutuhan Ruang Workshop dan Pendidikan

\begin{tabular}{|l|l|}
\multicolumn{1}{|c|}{$\begin{array}{c}\text { Jenis } \\
\text { Kegiatan }\end{array}$} & \multicolumn{1}{c|}{$\begin{array}{c}\text { Kebutuhan } \\
\text { Ruang }\end{array}$} \\
\hline Pelatihan & Ruang kelas \\
\hline Pertunjukan & $\begin{array}{l}\text {-Exibitional hall } \\
\text {-Amfiteater } \\
\text {-Atrium }\end{array}$ \\
\hline Literasi & Perpustakaan \\
\hline
\end{tabular}

Tabel 2 menerangkan kebutuhan ruang kegiatan pelatihan (workshop) dan pendidikan.

3. Kegiatan Kuratorial dan Pengelolaan

Tabel 3. Kebutuhan Ruang Kuratorial dan Pengelolaan

\begin{tabular}{|c|c|}
\hline $\begin{array}{c}\text { Jenis } \\
\text { Kegiatan }\end{array}$ & $\begin{array}{l}\text { Kebutuhan } \\
\text { Ruang }\end{array}$ \\
\hline $\begin{array}{l}\text { Keluar } \\
\text { masuk } \\
\text { koleksi }\end{array}$ & $\begin{array}{l}\text {-Loading-dock } \\
\text {-Ruang dokumentasi } \\
\text {-Ruang karantina }\end{array}$ \\
\hline $\begin{array}{l}\text { Perawatan } \\
\text { koleksi }\end{array}$ & $\begin{array}{l}\text {-Ruang perawatan } \\
\text {-Ruang sterilisasi } \\
\text {-Ruang penyimpanan }\end{array}$ \\
\hline $\begin{array}{l}\text { Pengelolaan } \\
\text { museum }\end{array}$ & $\begin{array}{l}\text {-Ruang kantor } \\
\text {-Ruang rapat }\end{array}$ \\
\hline
\end{tabular}

Tabel 3 menerangkan kebutuhan ruang kegiatan kuratorial dan pengelolaan museum.
Hierarki ruang galeri disusun berdasarkan konsep perbedaan ketinggian ruang (bengkilas) yang terdapat di rumah adat Limas (Gambar 1) sesuai dengan kurun waktu perkembangan songket Palembang.

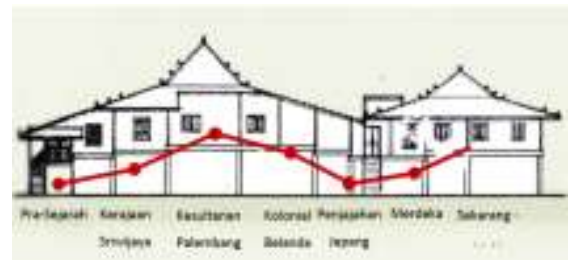

Gambar 1. Bengkilas pada Rumah Adat Limas. (Sumber: http://www.gosumatra.com/rumahLimas-sumatera-selatan/ dengan tambahan analisis penulis)

Sekuensi ruang pamer didesain agar tercipta pengalaman ruang yang berbedabeda sesuai dengan masing-masing tema galeri yang diceritakan. Seperti pada Gambar 2 berikut ini.

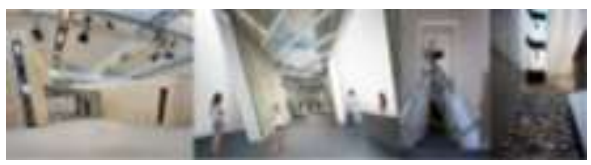

Gambar 2. Sekuensi Ruang pada Museum Yahudi Karya Daniel Libeskind di Jerman. (Sumber: http://libeskind.com/work/jewishmuseum-berlin/)

\subsection{Analisis Lokasi Tapak}

1. Tujuan: mendapatkan tapak yang sesuai untuk dibangun Museum Songket Palembang.

2. Dasar pertimbangan:

a. Dekat dengan/berada di kawasan Kampung Songket 30 Ilir, Palembang.

b. Sesuai dengan RTRW Kota

Palembang tahun 2004-2014.

c. Dekat dengan jalan besar dan dilalui oleh angkutan umum, sehingga mudah diakses oleh pengunjung.

3. Kesimpulan 


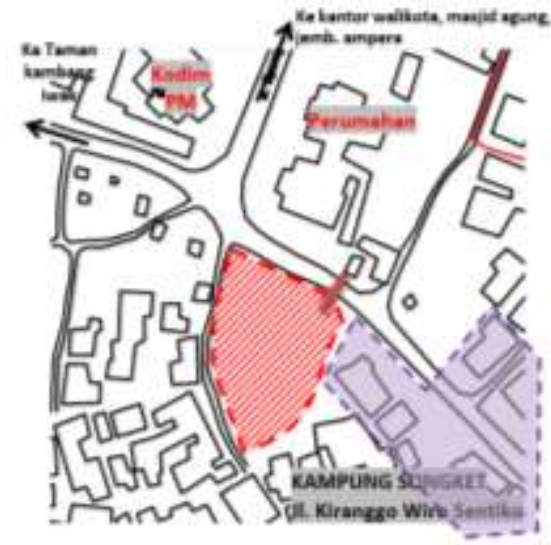

Gambar 3. Tapak Terpilih.

Tapak (arsir merah pada Gambar 3) berada pada Jalan Kiranggo Wiro Sentiko. Berada di simpul jalan menuju ke Kampung Songket 30 Ilir Palembang (ke tenggara, warna ungu pada Gambar 3), dari dan menuju ke pusat kota di mana terdapat Jembatan Ampera, Masjid Agung, dan Kantor Walikota (ke utara) serta Taman Kambang Iwak di sisi barat laut. Di utara tapak terdapat Kantor Kodim PM dan perumahan.

\subsection{Analisis Pemandangan dan Orientasi Massa Bangunan}

1. Tujuan: mendapatkan orientasi tampilan bangunan, sehingga tampilan bangunan terlihat menarik ketika dilihat dari luar tapak.

2. Dasar pertimbangan: potensi pemandangan ke dalam tapak dari arah simpul jalan.

3. Kesimpulan

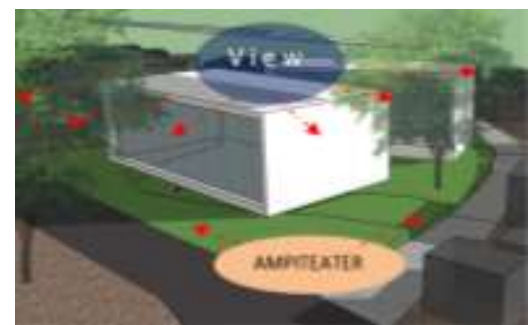

Gambar 4. Pemandangan dari Dalam dan ke Luar Bangunan.

Massa bangunan menghadap ke utara dengan sisi barat cenderung solid (Gambar 4) agar terhindar dari paparan sinar matahari.

\subsection{Analisis Gubahan Massa}

1. Tujuan: mendapatkan massa bangunan untuk Museum Songket Palembang yang sesuai dengan pendekatan Arsitektur Neo-Vernakular.

2. Dasar pertimbangan: analisis pemintakatan, analisis pemandangan, dan analisis pencapaian.

3. Kesimpulan

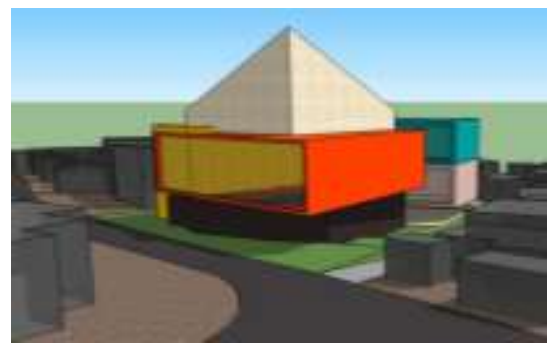

Gambar 5. Gubahan Massa.

Gubahan massa museum mengikuti garis sempadan tapak. Bangunan didesain panggung dengan lantai dasarnya dapat dimanfaatkan untuk area parkir. Di sisi depan dekat dengan sudut jalan dibuat amfiteater. Pada bagian atrium diberi atap piramida yang menjulang seperti pada Gambar 5. Ruang depan digunakan sebagai ruang penerimaaan, sebagai poin menuju ruang galeri di sisi timur, ataupun menuju exibitional hall di sebelah barat. Di lantai atasnya terdapat, perpustakaan, ruang kelas pelatihan dan kantor pengelola.

\subsection{Analisis Sistem Struktur}

1. Tujuan: mendapatkan sistem struktur yang tepat untuk bangunan museum.

2. Dasar pertimbangan: sistem struktur yang tepat untuk kondisi geologi tapak.

3. Kesimpulan

a. Struktur Atap 


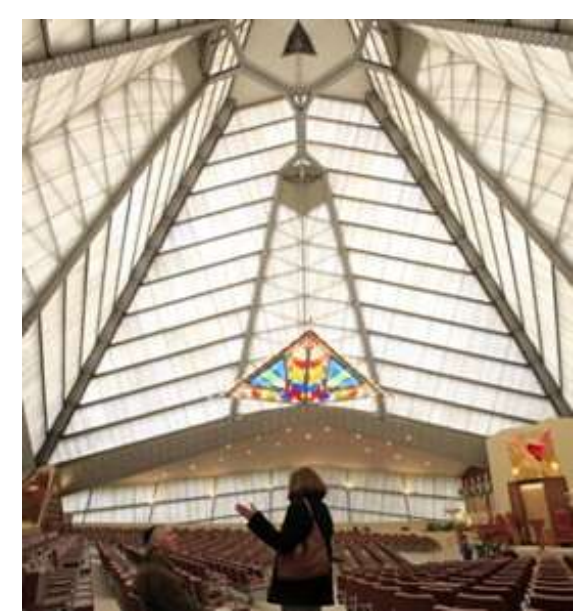

Gambar 6. Atap Sinagong Beth

Sholom, Pensylvania, F. L. Wright. (Sumber:

https://www.pinterest.com/pin/260786 634647041634/)

Atap piramida segibanyak yang menjulang di tengah bangunan didesain dengan sistem struktur rangka baja (Gambar 6).

\section{b. Struktur Pondasi}

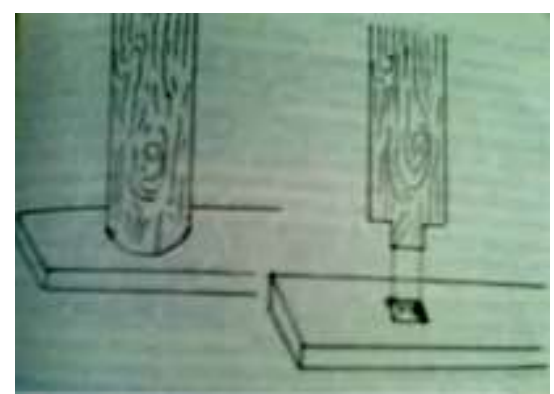

Gambar 7. Pondasi Kayu Rumah Adat Limas. (Sumber: http://isthaoctaviyantiarsi08.blogspot.co.id/2010/02/arsitekturPalembang.html)

Pondasi yang digunakan adalah pondasi telapak (footplat) dengan pertimbangan pondasi telapak serupa dengan pondasi rumah adat Limas menggunakan tiang balok kayu yang ditanam ke dalam tanah. Untuk menahan gaya dari atas, kolom tersebut diberi alas berupa papan di dalam tanah seperti pada Gambar 7.

\subsection{Analisis Tampilan Bangunan}

1. Tujuan: mendapatkan tampilan bangunan yang sesuai untuk bangunan Museum Songket.
2. Dasar pertimbangan: penampilan bangunan museum yang sesuai dengan pendekatan Arsitektur NeoVernakular.

3. Kesimpulan

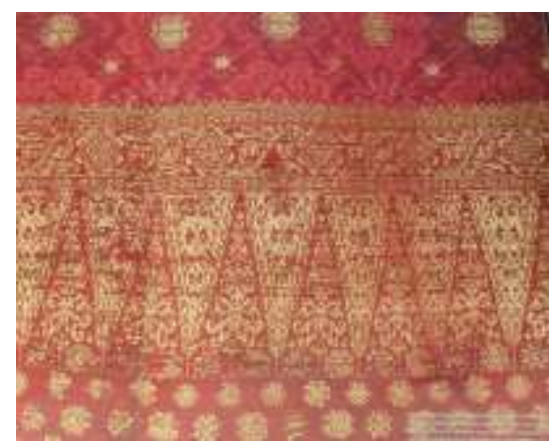

Gambar 8. Motif Tumpal Rebung pada Kain Songket Palembang.

(Sumber: Jusuf, 2012)

Material bangunan yang digunakan sebagai kulit luar adalah menggunakan cladding kayu artifisial sehingga tetap menampilkan bahasa arsititektur rumah adat Limas yang menggunakan dinding kayu. Detail pada fasad diambil dari motif songket Palembang (Gambar 8), yaitu motif pucuk rebung yang biasanya muncul pada bagian tumpal membentuk repetisi segitiga di tepi kain songket. Detail pada atap piramida mengambil stilasi motif berakam.

\section{KESIMPULAN (KONSEP DESAIN)}

Nama : Museum Songket

Lokasi : Jl. Kiranggo Wiro Sentiko

Luas lahan $\quad: 1754,71 \mathrm{~m}^{2}$

Luas Bangunan : 2618,41 $\mathrm{m}^{2}$

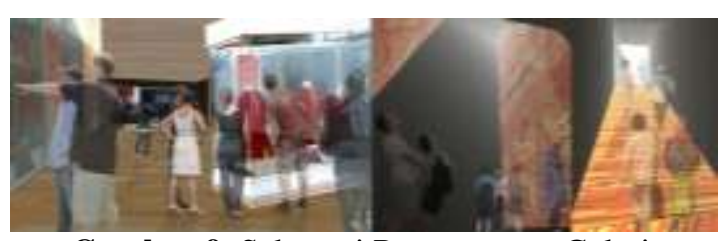

Gambar 9. Sekuensi Ruang-ruang Galeri Museum Songket Palembang.

Konsep rancangan Museum Songket Palembang menerapkan prinsip-prinsip Arsitektur Neo-Vernakular. Konsep bengkilas diterjemahkan dalam bentuk hierarki ruang-ruang galeri (Gambar 9) 
menciptakan pengalaman ruang yang berragam sesuai dengan cerita dalam galeri.

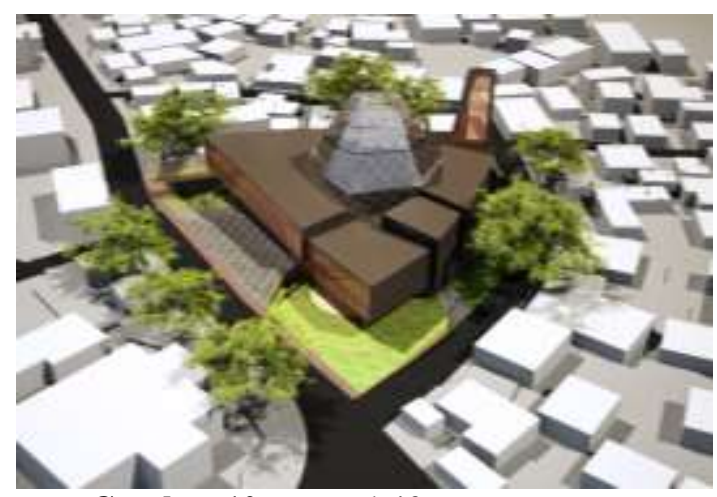

Gambar 10. Perspektif Mata Burung.

Bangunan museum didesain panggung, dengan lantai dasar sebagai area parkir kendaraan. Gubahan massanya merupakan interpretasi dari bentuk siluet rumah adat Limas. Atap piramida segibanyak menjulang di tengah bangunan, dengan material skylight dengan detail motif songket berakam (Gambar 10). Didesain seolah melingkupi seluruh kulit permukaan bangunan, seperti pada penggunaan kain songket sebagai keradong yang menutupi kepala (atap) dan kemudian menjuntai melingkupi seluruh permukaan bangunan.

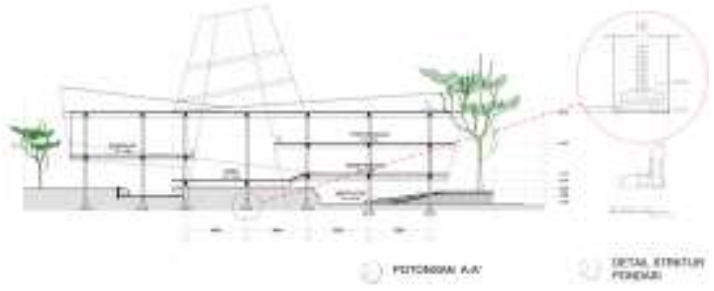

Gambar 11. Potongan Struktur.

Sistem struktur yang digunakan tertera pada gambar potongan (Gambar 11) yaitu sistem pondasi telapak (footplat) yang merupakan interpretasi analogi dari sistem pondasi rumah adat Limas yang menggunakan balok kayu yang dipasakkan ke papan (Gambar 7) sebagai alas (lantai kerja) di dalam tanah.

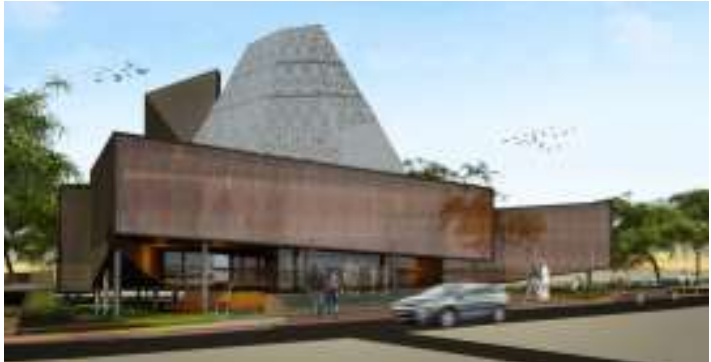

Gambar 12. Perspektif Fasad Depan Museum Songket Palembang.

Gambar 12 menunjukkan detail motif pucuk rebung yang diterapkan pada fasad bangunan dan stilasi motif songket berakam pada atap piramida.

\section{REFERENSI}

BPS Palembang. 2014. Palembang Dalam Angka 2014.

Jusuf, Herman. dkk. 2012. Pendar-pendar Kilau Pelangi: Wastra Adati dari Selatan Sumatera. Jakarta: Livimbi Media

Kartiwa, Suwati. 1986. Kain Songket Indonesia. Jakarta: Djambatan

Sumalyo, Yulianto. 1997. Arsitektur Modern Akhir Abad XIX dan Abad XX. Yogyakarta: Gadjah Mada University Press

http://www.gosumatra.com/rumah-Limassumatera-selatan/

http://isthaoctaviyantiarsi08.blogspot.co.id/2010/02/arsitekturPalembang.html

http://libeskind.com/work/jewish-museumberlin/

https://www.pinterest.com/pin/26078663464 7041634/ 